\title{
Multiple alpha sources and portfolio design
}

Marielle de Jong ${ }^{1} \cdot$ Dan diBartolomeo ${ }^{1}$

Published online: 31 August 2021

(C) The Author(s), under exclusive licence to Springer Nature Limited 2021

The investment management profession has come a long way since Nobel Laureate Harry Markowitz (1952) introduced Modern Portfolio Theory (MPT) in the early 1950s. At the time, the term modern made reference to the methodical use of return and risk estimates when building investment portfolios. The idea that performance opportunity together with the risk-taking involved in seizing that opportunity can be enciphered methodically was new. The central position of expert appraisals while handpicking assets gave way to a systematic approach to portfolio construction through meanvariance optimization. MPT enthusiasts started mapping out assets over the advocated return-to-risk grid to let quadratic programming algorithms find optimal combinations for them. Mean-variance optimization was hot in that period, for example for solving naval logistics problems, as we can trace back from Harry's first publications.

The Capital Asset Pricing Model (CAPM), developed over ten years later (Sharpe 1964), reinforced the Cartesian mind-set. This model associates performance opportunity to the alpha component of the asset return (Jensen 1968), while the beta component comprises the risks involved in seizing the opportunity. The alpha-beta decomposition rule relies on a single input: on the market index, which was conveniently made available by data vendors. The simplicity of the model accentuates its beauty. Though the thoughts behind the CAPM are more complex than presented here, simplified calculations (Elton et al. 1978) geared to find optimal solutions take the decomposition rule as is. It zooms in on combinations of assets where the weighted sum of alpha for given beta is maximized. Constructing portfolios in this manner has great advantages. It is tractable, trustworthy as it is empowered by the standing finance theories, and not for the least, it is scalable.

The shift from a discretionary toward a systematic approach to investing was broadened by the advent of the

Marielle de Jong

marielle.de-jong@grenoble-em.com

1 Grenoble Ecole de Management, Grenoble, France computer giving accelerated calculation power. The shift coincided more generally with the spirit of the time period. Large fields of macroeconomics and monetary policy theory were revolutionized by new dynamic models that conflicted with the old lines of thought. One of the inspirers was Nobel Laureate Jan Tinbergen, who is seen to be the godfather of the discipline of econometrics. He contributed to developing new techniques, which were in part borrowed from the sciences, destined to retrieve insightful information from macroeconomic data. The attention of economists was increasingly drawn to systematically processing large datasets. Number crunching became popular and for a few decades the norm.

In finance, the joy ride is lasting since, one may say, albeit in an ambiance of permanent debate. The assumptions that back up the standing models seem too good to be true. Fama and French (1992) stirred hefty debate in the 1990s by calling into question the assumption of a single risk factor that underlies the CAPM. They showed that two complementary factors, named value and size, make the risk definition more accurate. Judging by the astronomic number of downloads from Kenneth French' website, many practitioners acknowledge their findings and have in effect adopted the factors since. This development has not caused a halt though, nor a change of tack. The ride continues, flanked by two additional factors that attract additional debate. The value and size factors have become part of the mainstream concept of equity management to the point that they may actually embed systemic risk. What will happen on the day Professor French stops updating his website?

At this point, let us add our grain to the lasting debate on the value and size factors. We assert that these factors are merely corrections of an ill-specified market factor. Until the 2010s, when the design of market indices was first called into question, it was taken for granted that the market index, in the format delivered by the data vendors, was effectively capturing market risk. Little attention was paid to the turnover in the index, generated by new entrees systematically replacing old dropouts. From the view that the assets that are selected to enter the index are liable to bear a premium 
and that those condemned to leave may trade at a discount, a portfolio that is purposely sorted on asset valuation will artificially stand out. As to the size factor, the fact that market indices are capitalization weighted (thus reflecting the price behavior of large entities) gives plenty of space for a size effect to be left unaccounted for.

Our comment adds to the list of odd empirical findings and anomalies that have been highlighted over the years that are anomalous at least with respect to the standing theory. It is not evident how to decide whether the observation is the odd one out or whether the theory is at odds with market practice. Either way, the interest of the relentless flow of critics (and critics thereon) is that it encourages collective thought about the tools we use to invest. Where is the ride leading to next? That is the topic of this special issue. The articles it contains give an interesting view on how the art of portfolio management has evolved since the early days and on where it may be heading next. What to think of all that strikes at our views of finance theory and what credence to give it?

In the lead articles (a series of two), the authors Frank J. Fabozzi and Stephen Gorman make an extensive review of the various alpha sources that have been brought forward over the last decades and have been coined as the Alternative Risk Premia (ARP). The review is the first of its kind. In the first article, the authors discuss the principles on which the potential for abnormal return is based, whether it be a market anomaly, a systematic risk factor or a mere result of data snooping. The second article is a review of the literature on ARP itself. The class of ARP has made its appearance on the asset management scene very much like Graham Greene's character of The Third Man, in the sense that it appears as an esoteric third component carved out somewhere between the alpha and the beta component. The crux is that the new alpha sources are challenging the very setup of mean-variance optimization.

Dealing with the new alpha sources arising from multiple of performance opportunities, in the context of portfolio optimization, is the central theme of the articles that follow. In the third article, Bernd Scherer gives his thoughts on how to add alternative assets to an invested portfolio. He proposes a decomposition of the utility that the assets can add into three components, into a return enhancement, a diversification benefit and a hedge capacity. This work demonstrates how optimal allocations to the add-ins can be obtained by maximizing the added value along those three dimensions. He does this while taking a robust optimization approach whereby the solution best fits a large span of possible outcomes.

In the fourth article, Guillaume Simon and Charles-Albert Lehalle demonstrate what can happen if no precautions are taken. They show how a long-only fund manager who wishes to seize opportunity embedded in certain popular equity factors may end up with a highly concentrated optimal portfolio that would be worthy of a conviction-driven stock-picker! The authors give a precise account of the interaction taking place during the optimization process between the CAPM's alpha and beta component that leads to the perverse result. Their analysis points out where the limits of mean-variance optimization lie and so where auxiliary guidance or structure may be needed.

In the fifth article, named Factor Investing: Alpha Concentration versus Diversification, Lars Heinrich, Antoniya Shivarova and Martin Zurek study the question how to balance the concentration of performance drivers (alpha) in a portfolio with respect to the diversification of risk sources (beta) that are inherent. The authors do this in a context of multifactor investing. They conclude that a high concentration of alpha should be countered by imposing auxiliary constraints geared to diversify the risks in the portfolio. In line with the authors mentioned above, they conclude that extra diversification is necessary for long-only portfolios in particular.

In the sixth article, Wolfgang Bessler, Georgi Taushanov and Dominik Wolf compare a set of relatively modern investment strategies based on equity factors with more traditional sector-based investments. The authors observe that in normal times the factor strategies outperform, yet that in periods of market turbulence sector-based investments tend to do better. According to the authors, the reason lies in the level of concentration in the portfolios, in agreement with the view of the abovementioned authors. Sector-based portfolios are less concentrated and therefore more resilient in crisis periods, whereas factor portfolios are focused on the performance target, which does well if markets behave normally. The authors use on ETFs defined on US stocks between 1999 and 2020.

\section{References}

Elton, E., M. Gruber, and M. Padberg. 1978. Optimal portfolios from simple ranking devices. Journal of Portfolio Management 4 (3): $15-19$.

Fama, E., and K. French. 1992. The cross-section of expected stock returns. Journal of Finance 47 (2): 427-465.

Jensen, M. 1968. The performance of mutual funds in the period 1945 1964. Journal of Finance 23 (2): 389-416.

Markowitz, H. 1952. Portfolio selection. Journal of Finance 7 (1): 77-91.

Sharpe, W. 1964. Capital asset prices: a theory of market equilibrium under conditions of risk. Journal of Finance 19 (3): 425-442.

Publisher's Note Springer Nature remains neutral with regard to jurisdictional claims in published maps and institutional affiliations. 